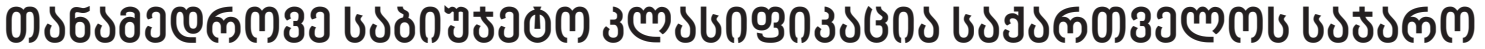

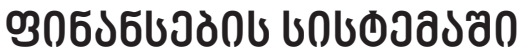

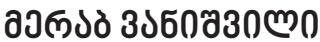

https://doi.org/10.35945/gb.2017.04.009

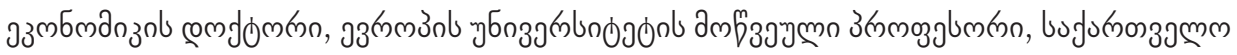

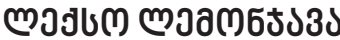

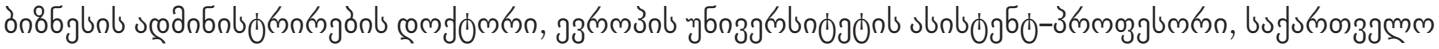

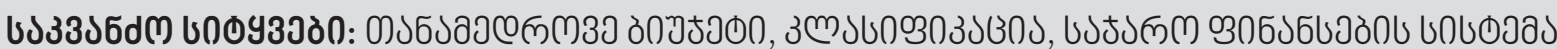

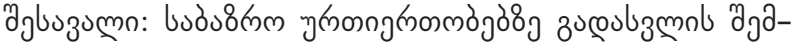

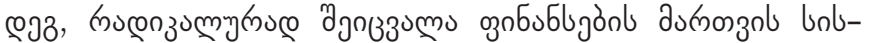

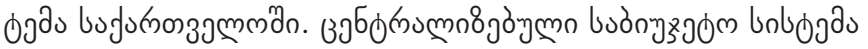

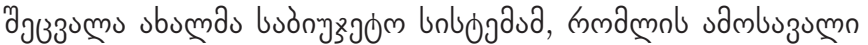

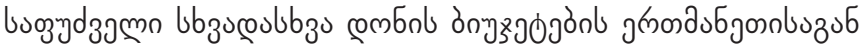

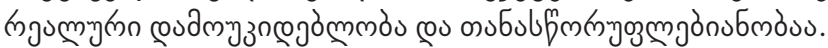

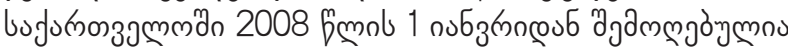

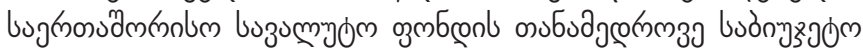

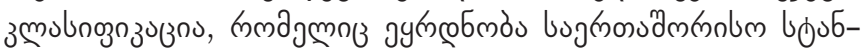

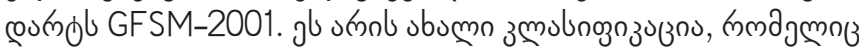

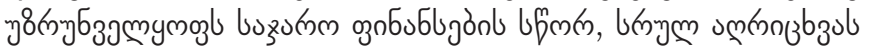

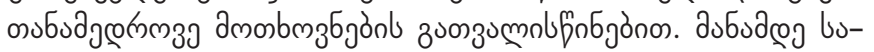

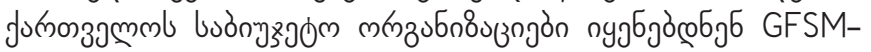

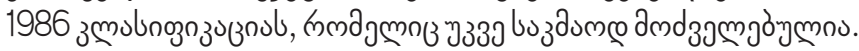

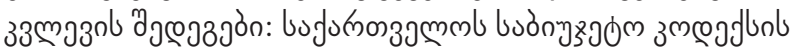

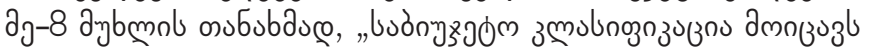

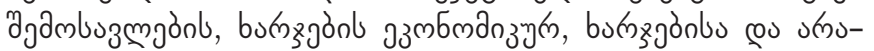

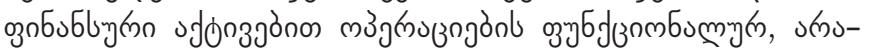

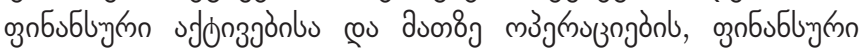

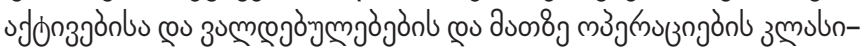

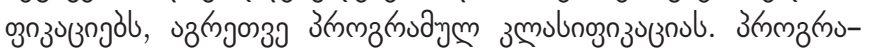

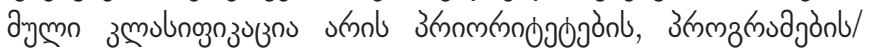

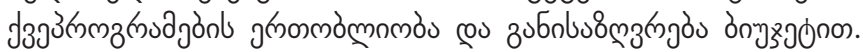

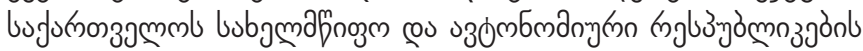

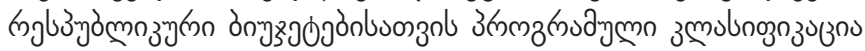

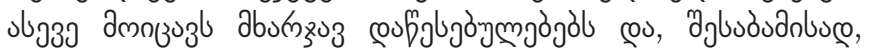

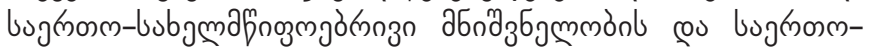

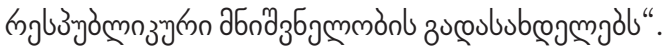

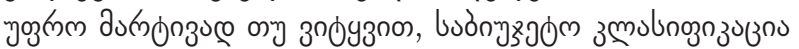

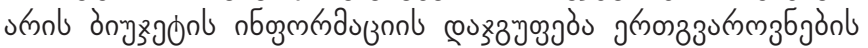

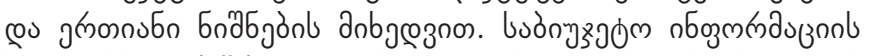

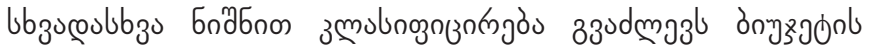

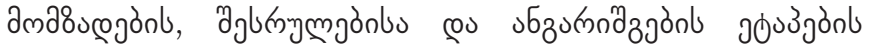

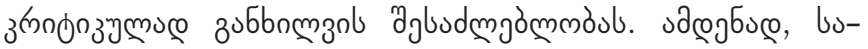

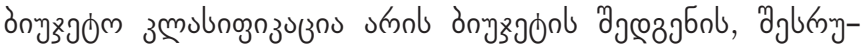

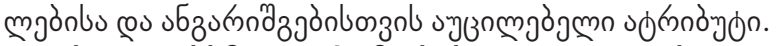

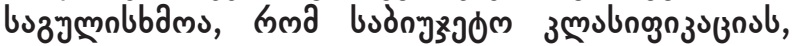

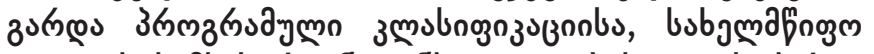

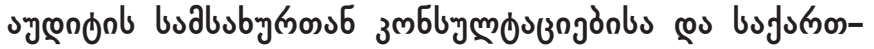

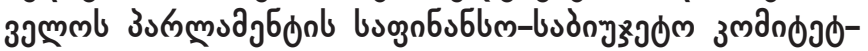

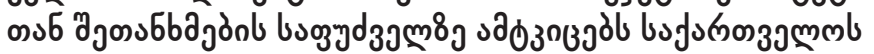

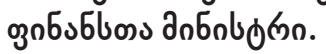

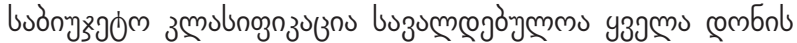

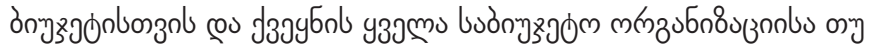

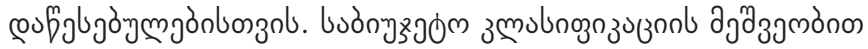

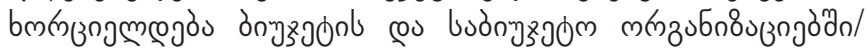

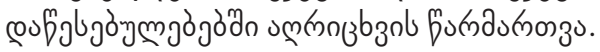

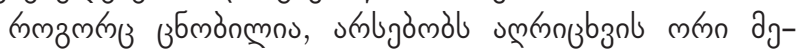

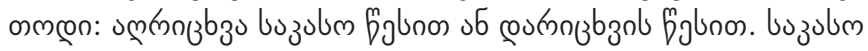

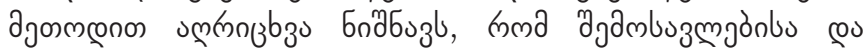

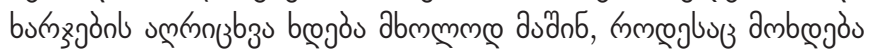

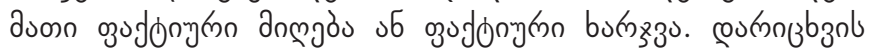

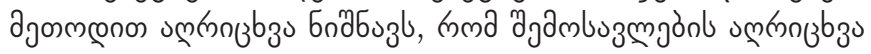

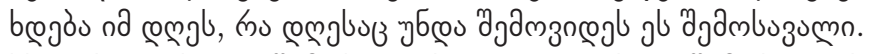

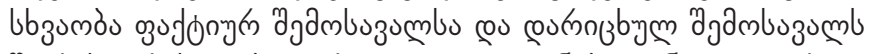

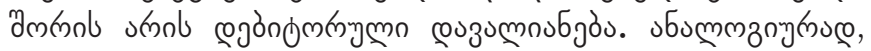

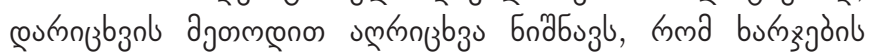

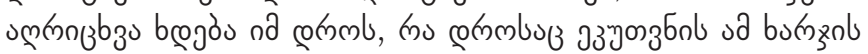

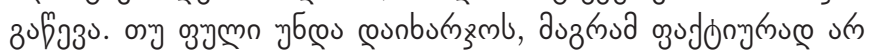

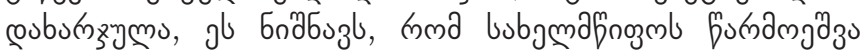

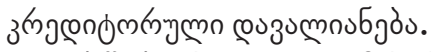

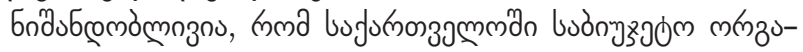

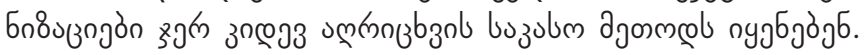

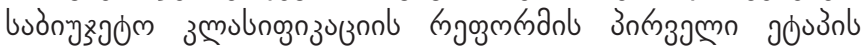

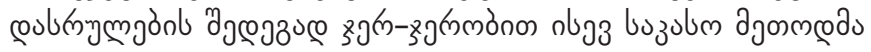

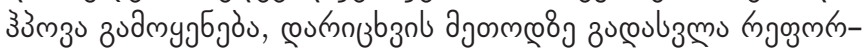

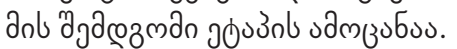

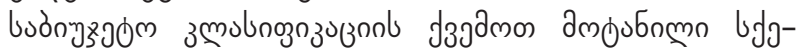
agòn эoुydb

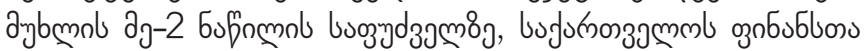

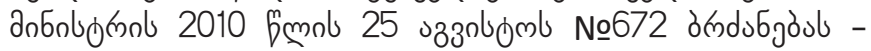

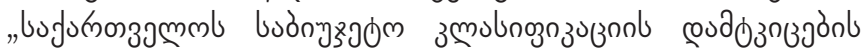

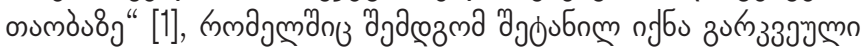

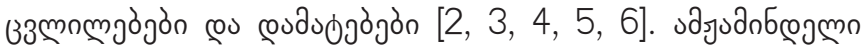

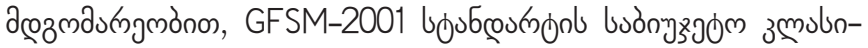

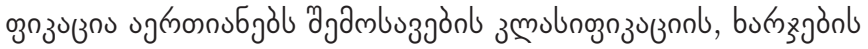

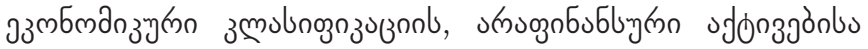

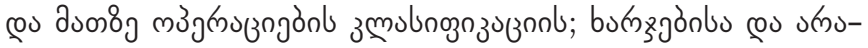

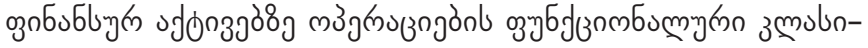

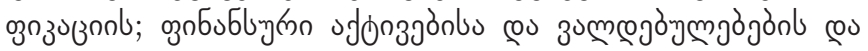

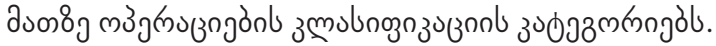

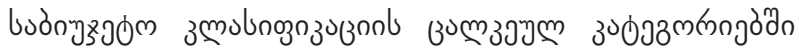

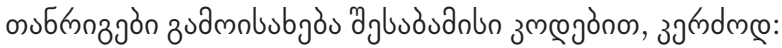




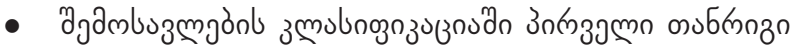

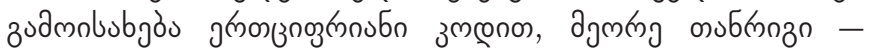

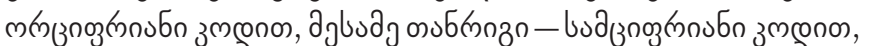

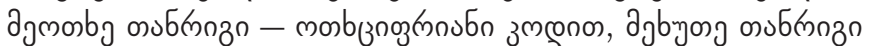

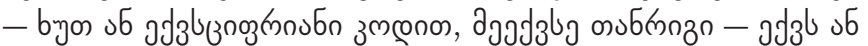

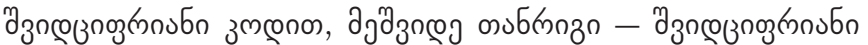

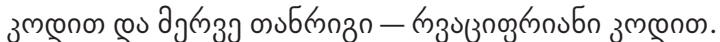

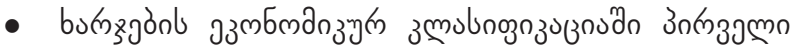

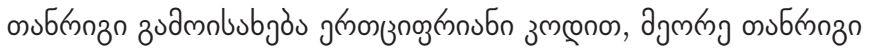

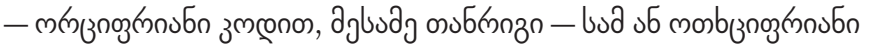

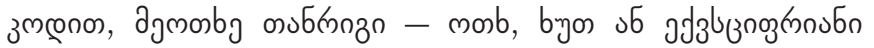

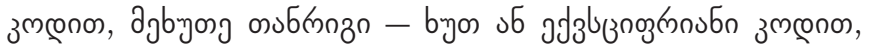

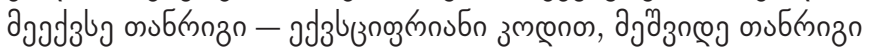

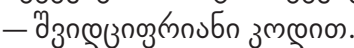

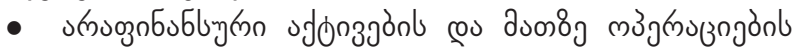
з

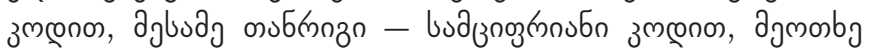

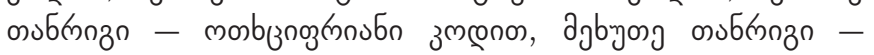

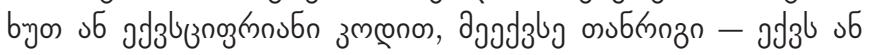

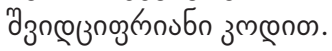

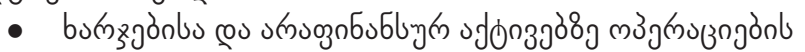

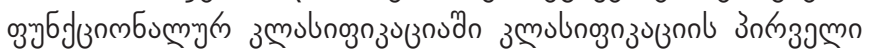

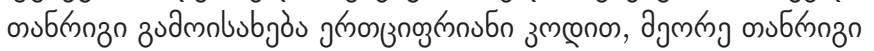

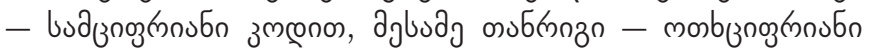

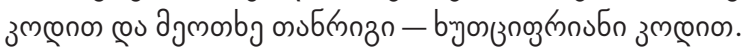

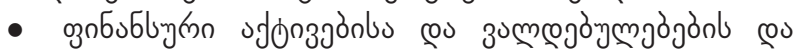

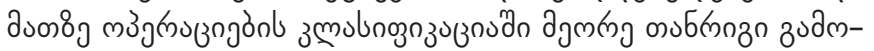

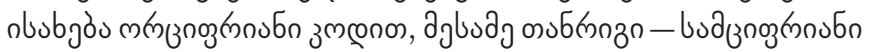

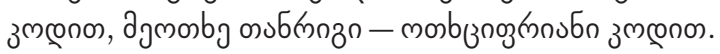

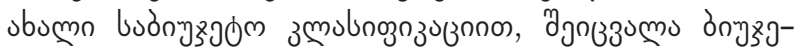

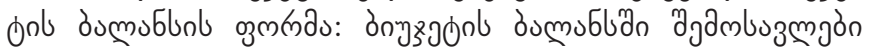

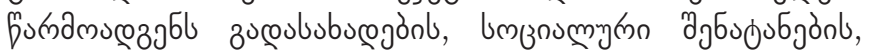

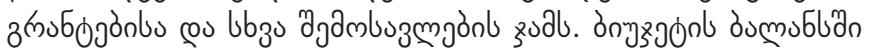

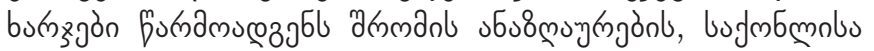

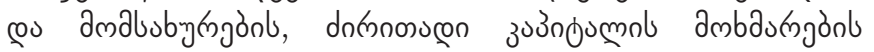

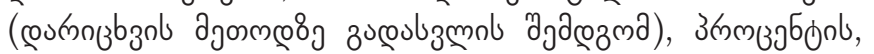

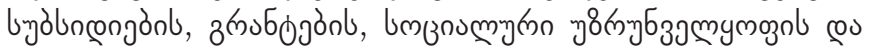
ubzu burnzgonol zual.

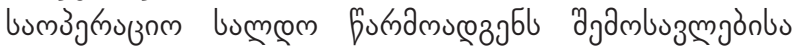

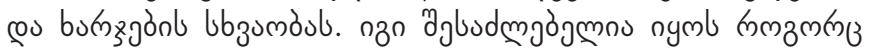

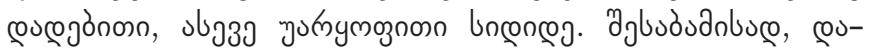

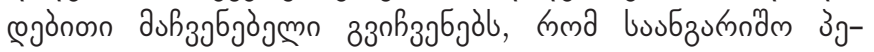

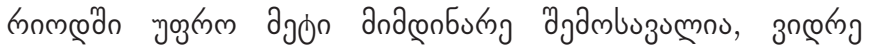

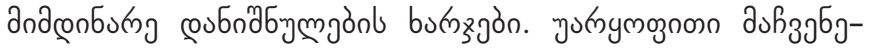

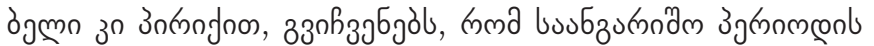

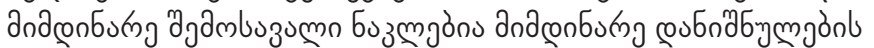

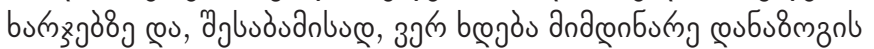
coz̧rmsjos.

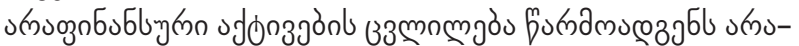

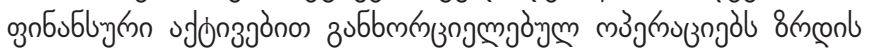

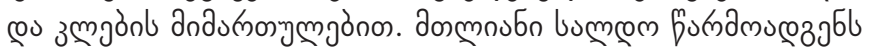

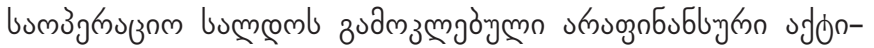

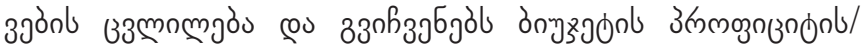

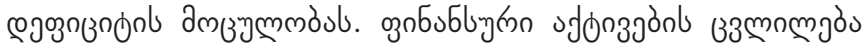

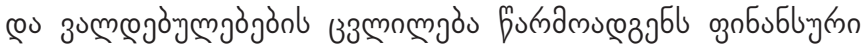

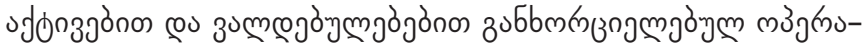

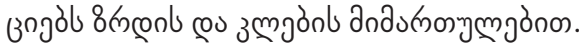

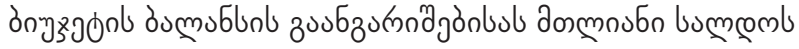

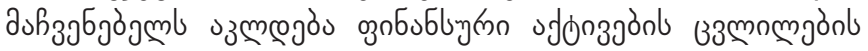

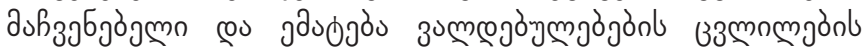

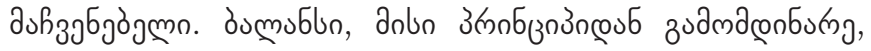

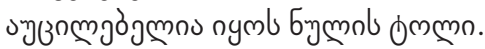

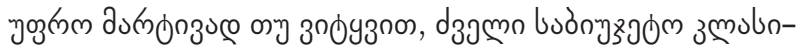

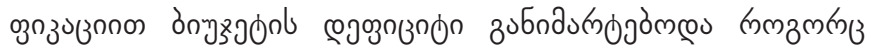

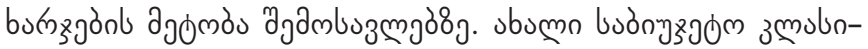

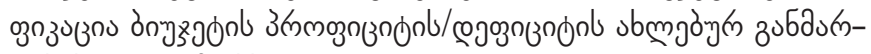

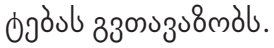

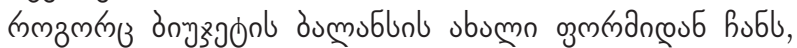

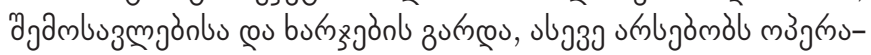

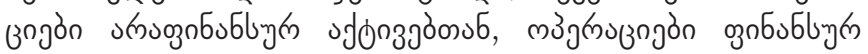

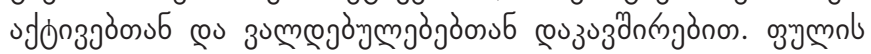

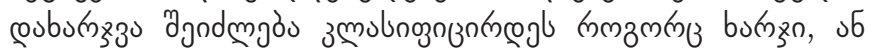

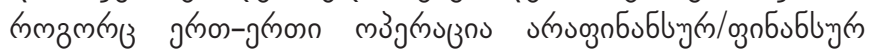

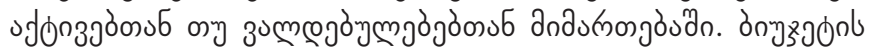

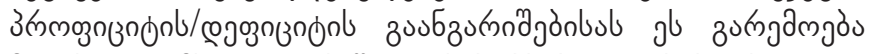

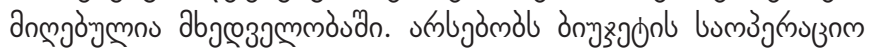

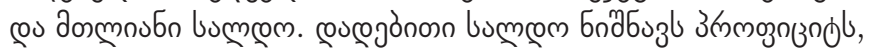

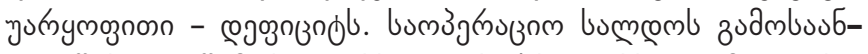

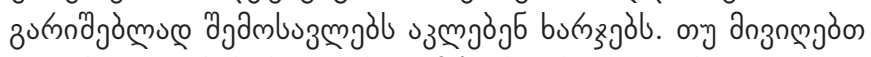

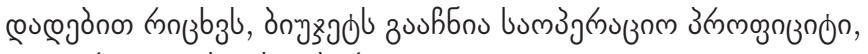

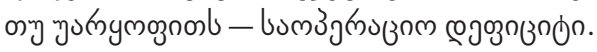

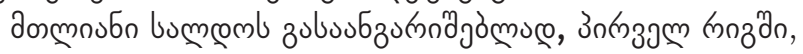

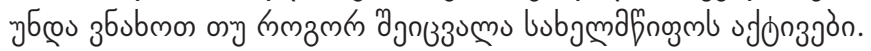

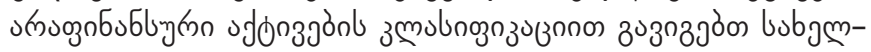

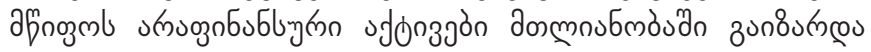

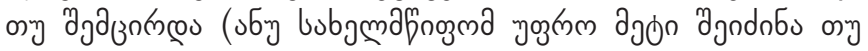

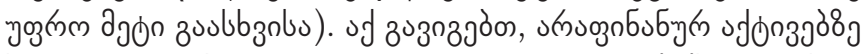

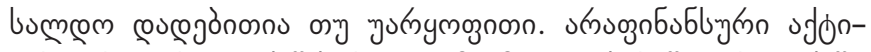

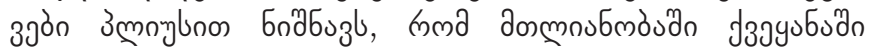

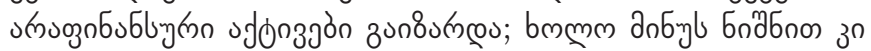

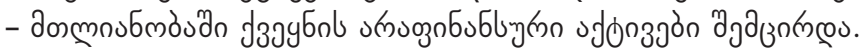

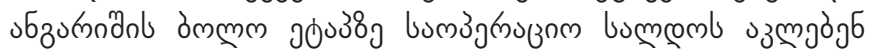

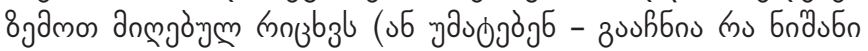

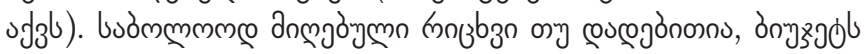

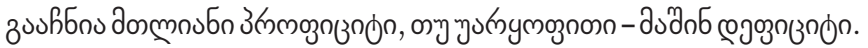

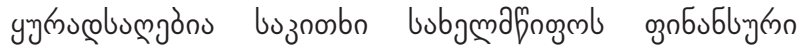

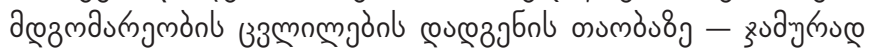

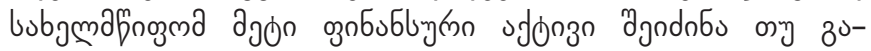

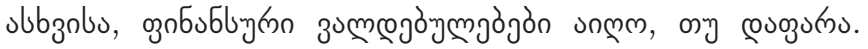

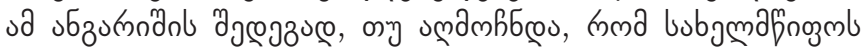

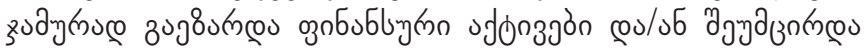

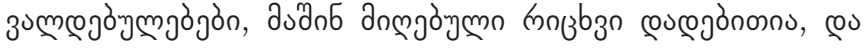
उntrofinon - yutruymognono.

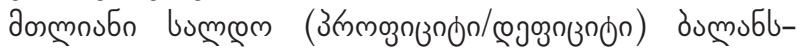

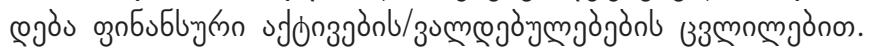

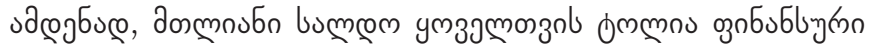




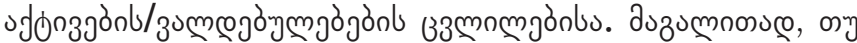

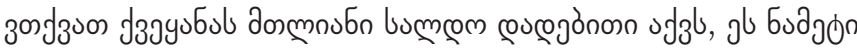

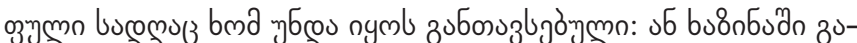

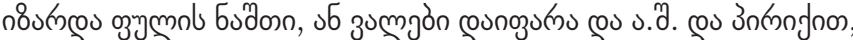

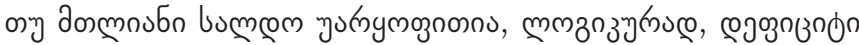

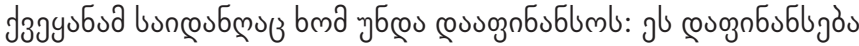

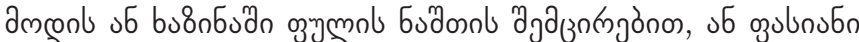

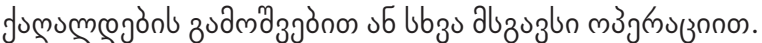

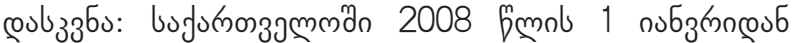

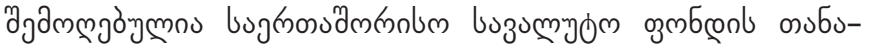

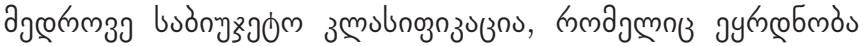

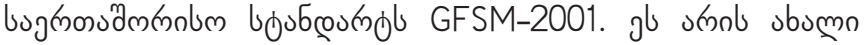

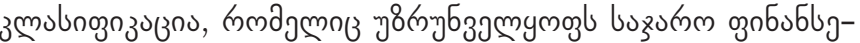

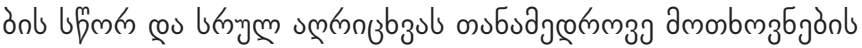

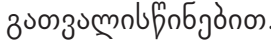

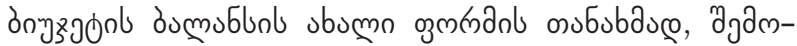

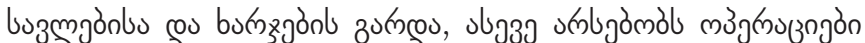

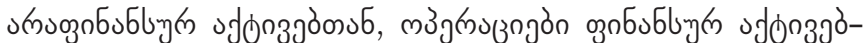

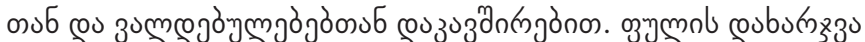

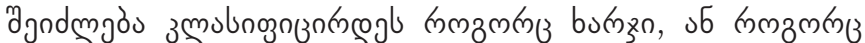

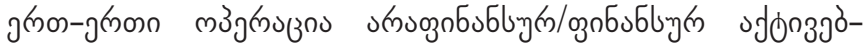

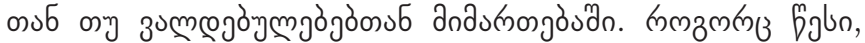

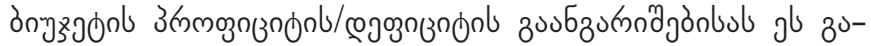

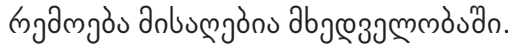

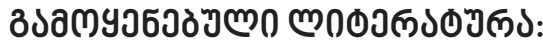

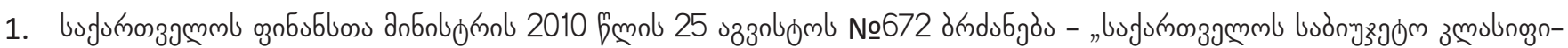

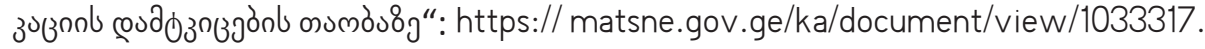

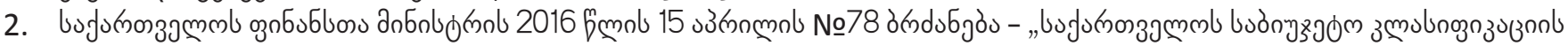

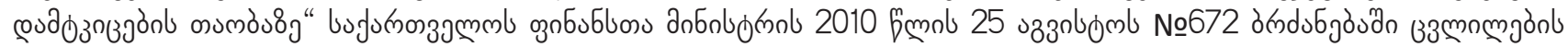
gobubnl gybubjo": https://matsne.gov.ge/ka/document/view/3255222.

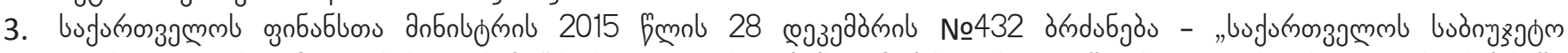

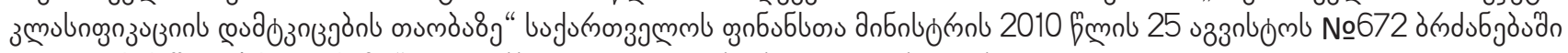

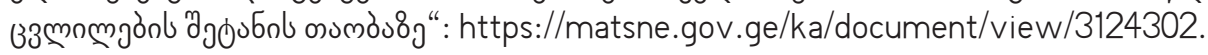

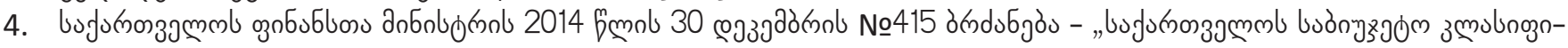

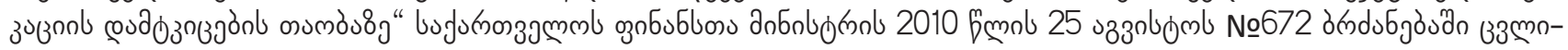

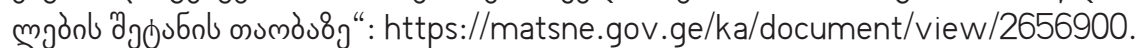

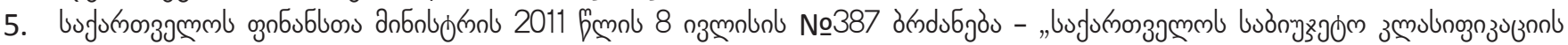

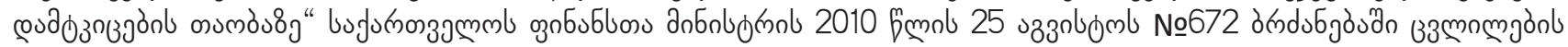

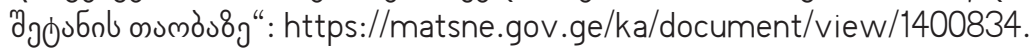

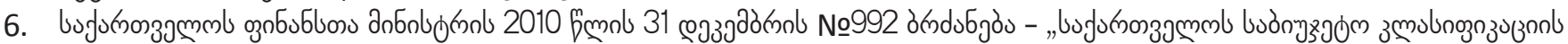

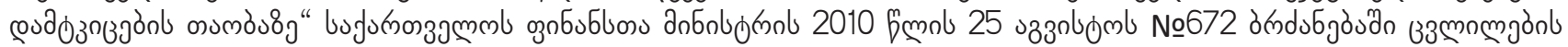
gobubnl gybubjo": https://matsne.gov.ge/ka/document/view/1167767. 


\section{MODERN BUDGET CLASSIFICATION IN THE PUBLIC FINANCE SYSTEM OF GEORGIA}

MERAB VANISHVILI

https://doi.org/10.35945/gb.2017.04.009

Doctor of Economics, Visiting Professor of European University, Georgia

LEKSO LEMONJAVA

Doctor of Business administration, Assistant Professor of European University, Georgia

KEYWORDS: MODERN BUDGET, CLASSIFICATION, PUBLIC FINANCE SYSTEM

\section{SUMMARY}

Market after the transition radically changed the financial management system in Georgia. The centralized budget system was replaced by a new budget system, based on independence and equality of budgets of different levels. The formation of income by own or regulatory taxes and freedom in their spending is considered.
Georgia on January 1, 2008 from the International Monetary Fund introduced the budget classification, which is based on international standards GFSM-2001. This is a new classification, which ensures the correct public finances, fully accounting for modern requirements. Prior to the budget of the organizations using GFSM-1986 classification, classification is already quite old. 